\title{
State regulation of import substitution in the agro-industrial complex of the Russian federation on the basis of foodstuff self- sufficiency need
}

\author{
Lyudmila Shabalina ${ }^{1, *}$, Lyudmila Kopteva ${ }^{2}$ and Angela Mottaeva ${ }^{3,4}$ \\ ${ }^{1}$ Donetsk National Technical University, Artema str., 58, Donetsk, 83000, Ukraine, \\ ${ }^{2}$ Saint-Petersburg State University of Aerospace Instrumentation,190000, 67, Bolshaya Morskaia str., \\ Saint-Petersburg, Russia \\ ${ }^{3}$ Moscow Region State University, Radio str., 10A, 105005, Moscow, Russia \\ ${ }^{4}$ Moscow State University of Civil Engineering, 26 Yaroslavskoye Shosse, Moscow, 109377, Russia
}

\begin{abstract}
In the article the need for state regulation of import substitution in the agro-industrial complex of the Russian Federation is founded upon the basis of food self-sufficiency call under conditions of sanctions. It is determined that when forming the mechanism of import substitution, an integrated approach is necessary, taking into account the peculiarities of the state development and the use of all types of potential. The existing trends in the functioning of the Russian Federation agricultural sector are noted. The main problem of the agro-industrial complex of the Russian Federation is revealed to be the lack of state support and funding, as well as the drawbacks of state regulation. It was revealed that, despite the identified positive tendencies in the development of the agro-industrial complex, with the purpose of stabilization it is necessary to upgrade the technical and technological spheres on the basis of an innovative approach to scientific and technological developments in all sectors of the agroindustrial complex. It was also pointed out to the fact in the sphere of food supply, an effective import substitution policy is possible provided that conditions for the development of Russian production of competitive food products are created. It is advisable to form import substitution on the basis of a closed production cycle within the state, in which producers are involved in supply and delivery chains directly to trading enterprises, and that requires improvements of the interaction system of all market actors. At the same time, producers are supposed to be able to significantly increase income, and consumers are supposed to have favorable food prices. A model of import substitution state regulation mechanism in the agro-industrial complex of the Russian Federation on the basis of selfsufficiency need in food is proposed, which is a set of stages for the implementation of a certain sequence of actions where each of the twelve stages is specified. In the process of implementation of the proposed model significant advantages can be achieved in the economic, technical and organizational spheres of the agricultural sector.
\end{abstract}

\footnotetext{
*Corresponding author: luda_2270@mail.ru
} 


\section{Introduction}

Presently, the economic science is based on the idea that economic interests are directly dependent on needs, the materialization of which accompanies the emergence of relations of property subjects with economic agents. In view of this, economic interests are often understood as meaningful needs, which find their expression in the form of consumption of socio-economic benefits, under which are the results created by human labor in order to meet the individual's specific needs. The target purpose of the state agro-industrial complex (AIC) is utmost satisfaction of the population food needs.

The development of the agricultural sector is greatly dependent on the policies conducted by the regions. According to the President of the Russian Federation V.V. Putin's annual message to the Federal Assembly, there is a need to provide greater independence to the constituent entities of the Russian Federation to identify priority areas for the use of federal subvention to support the agro-industrial complex, as well as to increase the responsibility of regional authorities for the final results and efficient use of the resources received, for strengthening their economic base, solving problematic issues in the social sphere and housing and communal services.

The main role in the state economy is played by three areas of the agricultural sector, which are aimed at meeting the priority needs of the population. These areas include: agriculture; industries producing means of production for agriculture; and industries for the processing of agricultural products. In turn, the agro-industrial complex forms the state food market, ensuring the food security of the population.

In the report "On the Development Strategy of the Agro-Industrial and Fishery Complexes for the Period until 2030", the Minister of Agriculture of the Russian Federation D. Patrushev noted that “... in the recent years, the agro-industrial complex, including due to state support, has shown steady growth, is one of the main drivers for domestic economy and has a direct impact on ensuring sustainable socio-economic development of the Russian Federation." To achieve the provision of the country with foodstuffs, it is necessary to perform, first of all, technical and technological modernization of agricultural production as a whole. At the same time, "... the tasks will be solved, firstly, through the use of resourcesaving technologies and high-performance equipment. Secondly, due to the effective involvement of agricultural land in the circulation with a simultaneous increase in productivity and soil quality. Now the Ministry of Agriculture is working to create an appropriate state program. Within its framework, until 2030, it is planned to involve at least 10 million hectares of land in agricultural circulation" (Patrushev, 2020) [1].

\section{Problem Statement}

The research relevance results from necessity for state regulation of food self-sufficiency conditioned by external sanctions affecting the economic development of the Russian Federation.

The current political and economic situation in recent years has a great impact to the agro-industrial complex of the Russian Federation. On the one hand, the imposition of sanctions by the United States of America and the European Union negatively affected the provision of habitual foodstuffs to the population, and on the other, it became an incentive for the development of the country's agricultural sector. Mentioned conditions make it necessary to adapt the agro-industrial complex development strategy to the prevailing circumstances, especially regarding imports. 


\section{Research Questions}

Due to the negative impact of sanctions pressure on the development of the agro-industrial complex of the Russian Federation, there is an objective need to introduce a policy of import substitution of food products. In this connection, it is advisable to formulate a mechanism of import substitution based on an integrated approach, taking into account the use of the full potential of the state economy, which will allow to switch to self-sufficiency in food stuff, ensuring a balance of interests between the state, population and business, in which it is necessary to create a closed production cycle within the state. In these circumstances, it becomes highly important to develop a model of import substitution state regulation mechanism in the agricultural sector of the Russian Federation based on principle of self-sufficiency in food, the implementation of which can ensure significant results not only in import substitution, but also in laying the foundation for export orientation of the complex.

\section{The purpose of the study}

To analyze the significance of state regulation of the policy of import substitution in the agro-industrial complex and food self-sufficiency in the Russian Federation is the purpose of the study conducted.

\section{Research Methods}

In the research process, a number of scientific methods were applied, namely statistical, general logical and theoretical. However, the study involves the use of empirical methods: observation, experiment, measurement, comparison. The work was based on the objectivity, consistency and concrete character of ongoing research activities.

According to G. Kleiner, the economy acts as a kind of connecting material that ensures the territorial unity of the country, which is obliged to increase the intensity of use of various types of resources, including the territory. The existence of weak ties between the economies of individual regions slows down the spreading of innovations, hinders the optimization of resource distribution, exacerbates the socio-economic differences of regions, lowers the potential of the economy as a whole, and also threatens the loss of economic independence of the state (Kleiner, 2013) [2, p.22].

O. Belokrylova notes regarding the forced import substitution in the modern Russian Federation that ".... if the goal of the import substitution strategy after the 1998 crisis was to accelerate economic development, now it has transformed into a compelled need to ensure the sovereignty of the country in foreign trade under high geopolitical risks. Consequently, the modern import substitution strategy for Russia is compelled, the US and EU economic sanctions have forced us to this."

S. Bordunov considers import substitution as minimizing not imports per se, but precisely these risks. According to him, the current task of import substitution policy is to create a system of incentives to support national production of import substitution products, competitive both in the domestic and foreign markets (Bodrunov, 2015) [3, p. 8].

V. Plotnikov and Yu. Vertakova link the course on import substitution with foreign policy and foreign economic factors of recent years, which are associated with the global economic crisis of 2007-2009. As scientists note, “... the majority of the causes that gave rise to it have not disappeared, the problems of generating the crisis development of the world socio-economic system are not resolved, but only "frozen" (Plotnikov, 2014) [4, p. 38]. 
It should be noted that a significant threat to the food security of the Russian Federation is its dependence on food imports, which reduces the economic potential and development of the state. This context indicates that in current prevailing circumstances it is vitally important to implement measures of state regulation of the policy of import substitution in the agro-industrial complex in order to provide food self-sufficiency of the Russian Federation.

\section{Findings}

The indicator of the depth of food deficit in the world tends to decrease, that means an imbalance between consumption and production, which negatively affects the condition of self-sufficiency in foodstuffs of the population not only in each particular country, but also throughout the world (Fig. 1).

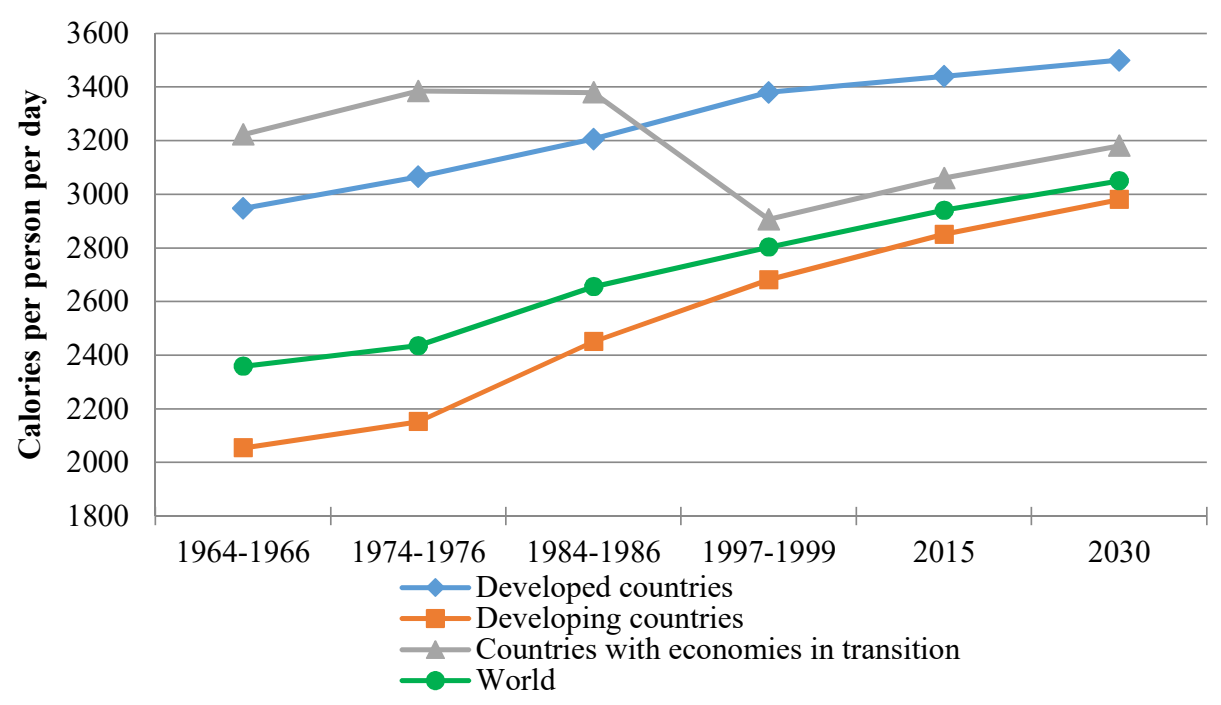

Fig. 1. The depth of the food shortage in the world (Compiled by the authors based on (Kopteva, Smolnitskaya, 2019) [5]).

High import dependence of the state significantly reduces the economic security of the country and infringes upon national interests. In exchange for receiving imported food and raw materials for its production, the country is increasingly giving up non-renewable natural resources and losing its place in the world market. An important aspect of ensuring food security is also the import of low-quality products, which in turn poses the most important strategic objective of the agrarian policy that is achieving self-sufficiency in quality of our own agricultural products [6, p.303]. In the context of import substitution, the role of state authorities is increasing, since they need to act as a guarantor of support for improving and modernizing the agro-industrial complex of the Russian Federation.

A comprehensive approach is required in resolving issues of import substitution, taking into consideration the peculiarities of both the country as a whole and regional components separately. It should be noted that there is a significant portion of imported food (coffee, citrus fruits, bananas, etc.) that cannot be produced in the Russian Federation, due to the peculiarities of the climatic conditions, which is an objective necessity.

Also, the necessity of state collaboration in the form of regulation and support is also indicated by the producers of agricultural products themselves. The imperfection of state 
regulation and the lack of state support occupy the leading positions among the most acute problems of the agro-industrial complex, which once again confirms the fact that the efficiency of the agro-industrial complex is impossible without a high-quality mechanism of interaction with the state.

Annually, the consulting company Deloitte determines the TOP-3 problems of the agricultural sector of the Russian Federation based on a survey of agricultural organizations (Fig. 2).

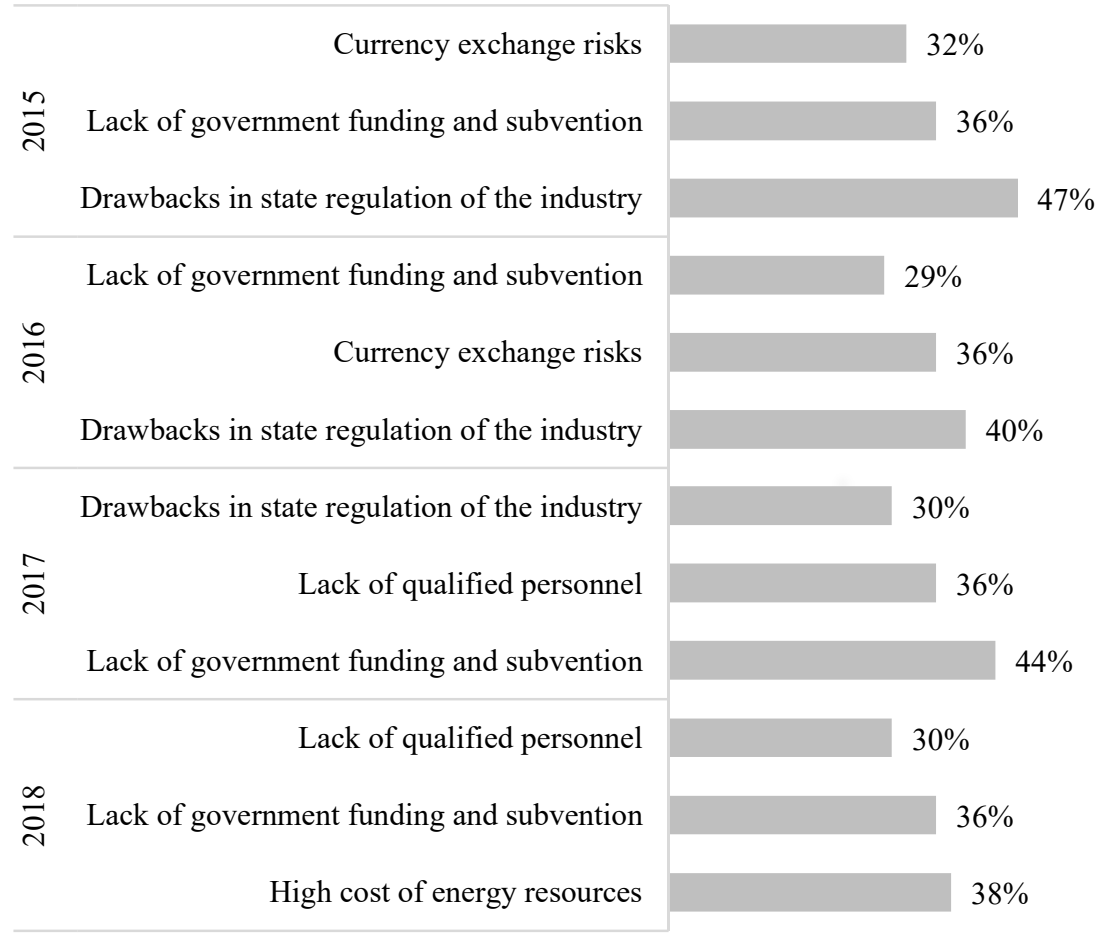

Fig. 2. TOP 3 problems of the agricultural sector of the Russian Federation (Compiled by the authors based on [7]).

Should be taken into account the fact that in many developed countries, import substitution of food products is not the priority direction of state policy in view of condition that the import of food products into the country from abroad is an objective necessity to meet the needs of the population and is not restricted from outside. Under the existing circumstances, this problem for the Russian Federation takes on a special character. It should be noted that the Russian Federation has great potential for the development of national food production. At the same time, the utilization of this potential is associated with a number of difficulties such as: natural and climatic conditions, which require an innovative approach to scientific and technological developments in the agricultural sector; weak integration ties between agricultural producers; lack or complete absence of specialized storage facilities for fruits and vegetables; long duration of the production cycle of some industries, for example, livestock sector. Nevertheless, in crop production the implementation of import substitution policies is quite possible.

Of course, absolute substitution of imported food products with Russian ones is not meant in view of the geographical and climatic features of the Russian Federation. At the same time, it is appropriate to replace imported food products which are permissible to 
produce in our natural conditions for the Russian analogues in accordance with the socioeconomic criteria of feasibility.

The socio-economic expediency of state regulation of the agricultural sector of the Russian Federation consists in the fact that national production should be primarily aimed at creating jobs and surplus value, as purchasing agricultural products abroad does not contribute to improving the standard of living in the country. It should be noted that the basis for the development of the rural economy is human capital for the formation of which it is necessary to create the motivation and socio-economic environment. The following conditions also have a negative impact on the development of the agro-industrial complex, these are low purchase prices from agricultural producers by food and processing wholesalers as well as by retail representatives; rising prices for energy and supplies; randomness of ownership of land and inefficient use of agricultural land by owners; lack of available financial instruments for project implementation. Thus, the development of effective state programs and the subsequent state regulation of the agricultural sector is one of the primary tasks of the state.

The main directions of agricultural development in the Russian Federation are reflected in the State Program for the Development of Agriculture and Regulation of Agricultural Products, Raw Materials and Food Markets for 2013 - 2025. [8]. An analysis of the structure of agricultural raw materials and food in the total value of Russian imports in the period of 2001-2018 indicates a tendency to decrease its share from $27.7 \%$ to $12.4 \%$, respectively (Fig. 3).

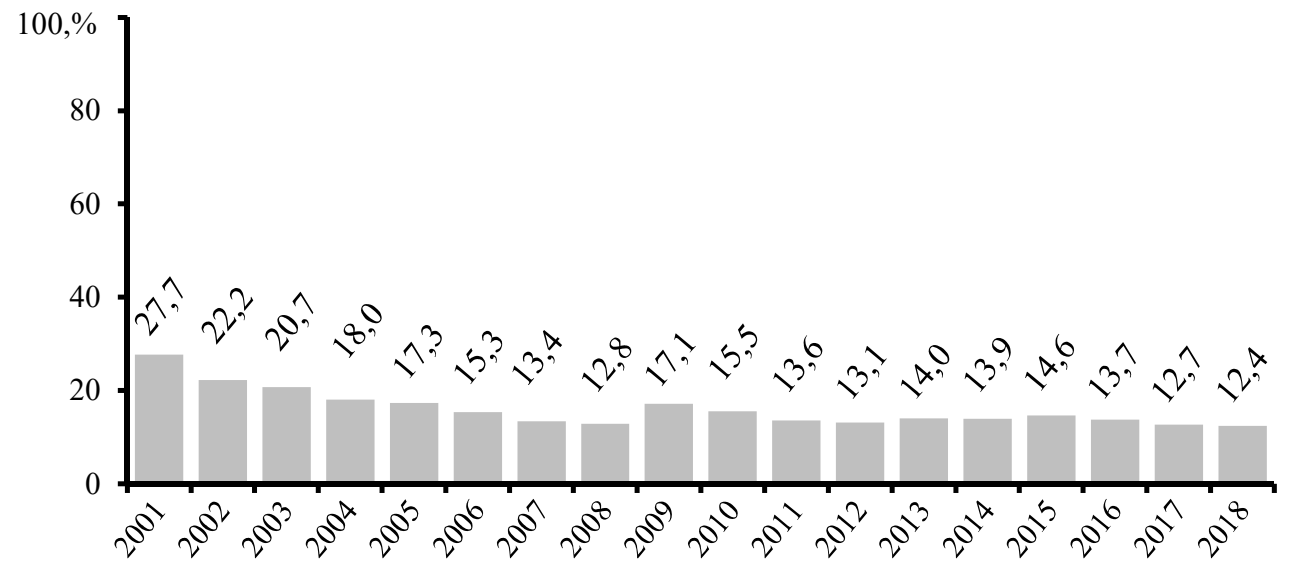

Fig. 3. Agricultural raw materials and food in the total value of Russia imports, $\%$.

It is appropriate to form an import substitution policy in the field of agriculture on the basis of the principle of closed production cycle within the industry, in which producers will be involved in supply chains directly to trading enterprises, which will require modernization of the system of interaction of market participants at all levels. At the same time, producers are able to significantly increase income, and for consumers it becomes possible to purchase food at lower prices.

It should be noted that import substitution does not always lead to an increase in the efficiency of local production, since in order to ensure the advantages of the domestic producer, it is necessary to establish import duties, which is not always contribute to the formation of fair competition in the domestic market and discourage national producers to produce competitive goods. Consequently, the policy of import substitution only for the exclusion of imported products from local markets is meaningless, such measures can lead to the formation of a shadow economy and black market. 
In the current economic and political conditions agro-industrial complex reforming is of great importance for the development of the country, it is aimed to improve the population level and quality of life. In connection with these circumstances, a comprehensive analysis of the general condition of the agro-industrial complex is necessary, which will allow determining the directions of state regulation. According to experts' opinion, it is necessary to develop agricultural infrastructure, reduce administrative barriers, identify and implement information systems for supporting the performing of agricultural enterprises, form and develop specialized credit institutions, provide agriculture with qualified personnel, and develop measures to stimulate the export of agricultural products.

Of particular relevance is the ability of the constituent entities of the Russian Federation to independently provide themselves with necessary food. In connection with circumstances mentioned, it is necessary to develop a mechanism that can control the dynamics of the level of self-sufficiency in food products both in the regions and in the country as a whole. R. Mansurov and A. Zasedova have developed a methodology for rating the level of food products self-sufficiency. Using this methodology for assessing the level of self-sufficiency in food products, including the main types of food at the regional level, it is possible to determine which sectors of the agricultural sector are lagging. The self-sufficiency rating of basic foodstuffs at the federal and regional levels can be calculated using the formula (Mansurov, 2017) [9]:

$$
R=\frac{\sum_{i=1}^{n} C f c}{\sum_{i=1}^{n} C c i},
$$

where $\mathrm{R}$ is the rating value of self-sufficiency in basic food products;

$-\mathrm{i}=1 \ldots, \mathrm{n}$ is the number of categories of basic food products used in the calculation;

- Cfc is a conditional deviation of actual and normative indicators;

- $\mathrm{Ci}$ is a reference deviation of actual and normative indicators

The deviation values of the actual and normative indicators are reduced to the conditional form:

- if the deviation is $\mathrm{Ci} \geq 1$, that is, the provision with the food product is complete or excessive, then $\mathrm{Cfc}=1$;

if $\mathrm{Ci}<1$, then $\mathrm{Cfc}$ remains at the level of the calculated deviation.

N. Shagayda and V. Uzuna in the calculations of food independence, actually identifies the level of provision of products, which is calculated by the formula (Shagayda, Uzun, 2015) [10]:

$$
F I=\left(\frac{V R}{V C}\right) * 100
$$

where FI is food independence, $\%$;

VR is the volume of resources that can be calculated as the sum of the output and changes in the balance of its stock (thousand tons);

$\mathrm{VC}$ is the volume of industrial and personal consumption within the country, (thousand tons).

This methodology is close to the algorithm for calculating food independence proposed by the Ministry of Agriculture of the Russian Federation, however, it draws attention mostly not to production, but to personal consumption. As a result, using the same criterion, it's possible to calculate the level of food independence in various ways and the results will be completely different $[11,12]$. 
It should be noted the mechanism of state regulation of import substitution of the Russian Federation is based on the updating and sale of regional agricultural products by means of achieving competitive advantages in the technical, economic and organizational fields. In this regard, a model has been developed for the mechanism of state regulation of improving the agro-industrial complex in the context of the implementation of the import substitution and food self-sufficiency strategy, which will create the conditions for agricultural activity conducive to achieving the set goal and fulfillment of the developed action plan. This model consists of the following parameters: 1) the process of formation and development of import substitution in the agro-industrial complex; 2) the mechanism of coordination of AIC institutions activity. Fig. 4 specifies the functional parts of the proposed model.

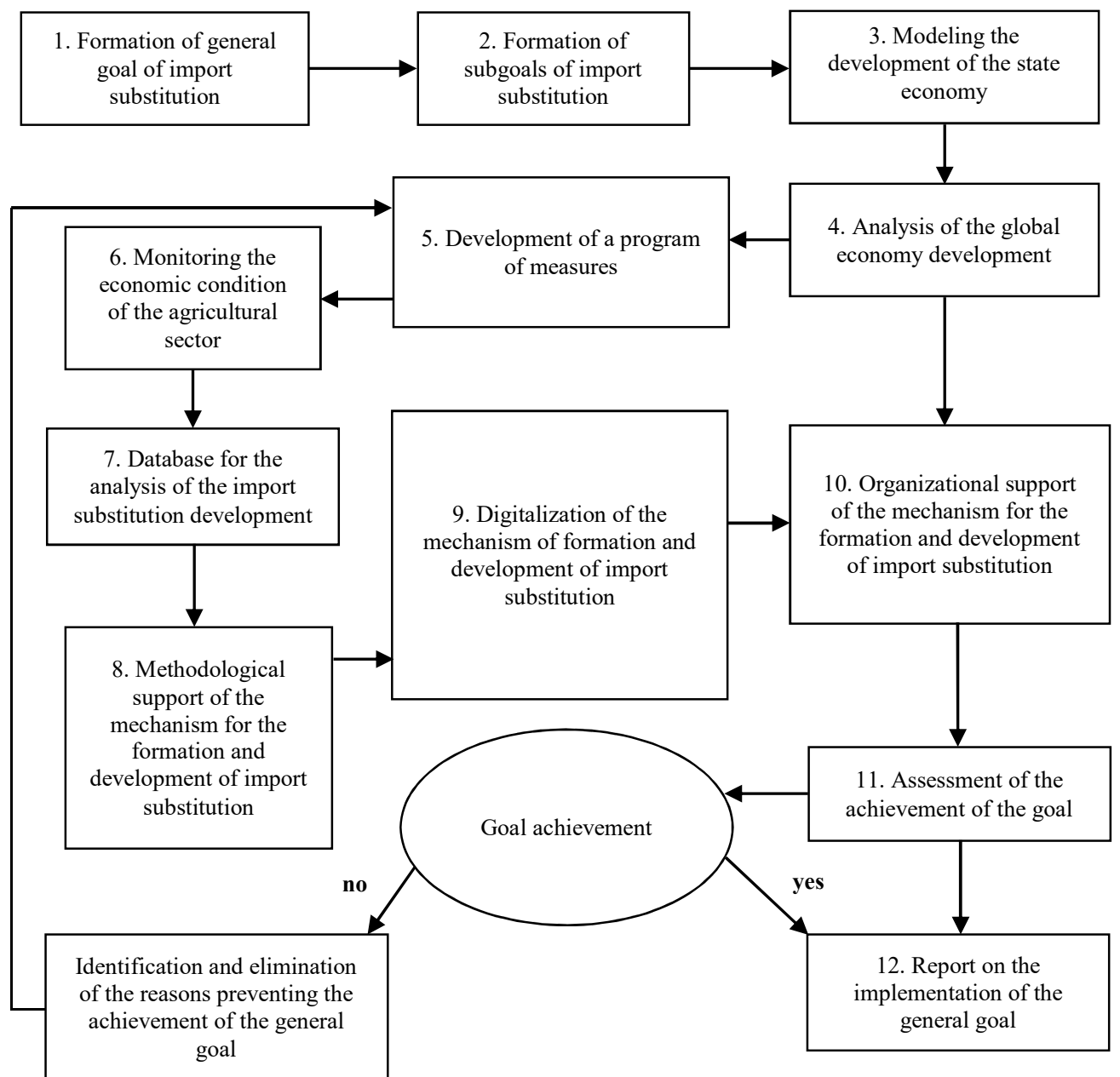

Fig. 4. A model of the state regulation mechanism in the context of import substitution strategy implementation and self-sufficiency in food provision of the Russian Federation.

The proposed model of the state regulation mechanism in the context of the implementation of the strategy of import substitution and self-sufficiency in the food sector of the Russian Federation is a complex of stages for the implementation of a certain sequence of actions where each stage is specified.

A detailed scheme of the state regulation policy of import substitution in agro-industrial 
complex and food self-sufficiency is presented in the following stages.

Stage 1. Formation of the general goal of import substitution. It is advisable to formulate the goal as creating conditions for the development of the agro-industrial complex on the basis of own output of products and increasing competitive advantages with the purpose of replacing imported goods with national ones. At this stage, it is necessary to reflect the specific positive result which are planned to be achieved.

Stage 2. The formation of subgoals of import substitution. At this stage, definite tasks are specified, the achievement of which will allow to obtain a positive effect, described in the previous part. It is important to correctly formulate the tasks, indicating the execution period and in quantitative terms of the target indicators of performance. Subgoals are determined for implementing the improvement in the agro-industrial complex under the conditions of the import substitution strategy realization. The authorities responsible for the development of sub-goals should be determined.

Stage 3. Modeling the development of the state economy. At this stage, an expert group is formed, whose task is to assess the goals set, identify the weaknesses and strengths in the potential development of the agro-industrial complex through the use of expert assessments and economic statistical methods, that is aimed to maximize the interests of national food producers.

Stage 4. Analysis of the development of the global economy. In the current conditions of the development of the world economy, it is important to take into account the system of international economic relations of the state, since in the context of the implementation of the import substitution strategy in the food sector they are the integral parts of an expert assessment of the agricultural sector development.

Stage 5. Development of a program of measures. This document is developed on the basis of expert assessment by authorized state authorities, after which the sources of financing and responsible executors from the Committee on the agro-industrial complex and the relevant government bodies are determined. Consider the proposed activities of the program:

- provision of subsidies and tax benefits to agricultural enterprises;

- granting bank loans to agricultural enterprises on favorable terms for the implementation of innovative activities;

- digitalization and modernization of technological processes for the production and processing of agricultural products;

- prevention of spreading and elimination of diseases of livestock and poultry;

- $\quad$ simplification of registration of farms;

- attraction of private investment in the agricultural sector at the expense of the profits of national enterprises;

- financial support for rural communities to improve living conditions;

- conducting market research to determine consumer preferences (taste characteristics of food, especially in the appearance and packaging of goods);

- organization of agricultural products fairs of own production.

Stage 6. Monitoring of the economic condition of the agro-industrial complex is performed on the basis of established criteria of the tasks implementation, which may be the following indicators: grain harvesting; picking vegetables and fruits, livestock for slaughter; production of meat and meat products; production of milk and dairy products; milk per cow; egg picking; crop production revenue and net profit; livestock revenue and net profit; accounts payable of agribusiness; share of imported products and their consumption by region. Relevant government bodies are appointed for monitoring.

Stage 7. Formation of a database for the development of the mechanism of import substitution involves a combination of quantitative and qualitative information. The main sources of data can be divided into the following types: state statistical reporting; opinion 
polls of the population; passports of territories and expert assessments.

Stage 8 . The methodological support of the formation of state regulation of import substitution mechanism involves the aggregate of all methodological documents (plans, programs, techniques, etc.), which present a systematic description of import substitution, which will subsequently be implemented in practice.

Stage 9. Digitalization of the mechanism of state regulation of import substitution is the creation, scheduling and aggregation of data flows for creating end-to-end chains and technologies from agricultural production to consumption with deep integration in related sectors of the digital economy with the purpose to increase labor productivity in agriculture and maximize the profits of enterprises in the industry.

Stage 10. The organizational and economic mechanism of state regulation of import substitution contains a set of economic and administrative-legal levers of influence, as well as forms of organization of social and production processes that ensure the functioning and sustainable development of agro-industrial complex and rural areas.

Stage11. Evaluation of the results achieved. At this stage, the responsible state authorities analyze the current values of the benchmarks. In case there is a deviation from the target values, the reasons for the failure to meet the planned indicators are identified, depending on which the plan is adjusted on the stage 5. Possible reasons for the failure to meet the targets: misuse of allocated financial resources; technological characteristics of new equipment do not meet production requirements; incorrect presentation of marketing research results; the appearance of the new competitive imported products on the market; irrational activity of certain sectors of the agro-industrial complex (the use of more expensive raw materials, which increases the cost of production); deliberate misrepresentation of results to create the appearance of plan fulfillment to responsible bodies; occurrence of force majeure circumstances (for example, natural hazards, technological disasters, etc.).

Stage 12. A report on the achievement of the goal includes effective indicators of the mechanism and is carried out by the established state authority.

Having described in detail the model for the formation of state regulation of import substitution in the agricultural sector mechanism under conditions of self-sufficiency in foodstuffs in the Russian Federation, it's possible to go on to draw up the mechanism of import substitution itself, where it is necessary to determine the bodies and enterprises involved in this process, as well as highlight the connections between the authorized state bodies of government and economic bodies of the state. Then, each of the subsystems of the proposed mechanism should be characterized in the context of the implementation of the import substitution strategy.

State regulation of import substitution and self-sufficiency in food is not possible without systemic mechanisms that ensure self-regulation of the mentioned processes, as well as identifying promising projects and enterprises to gain access to financial and organizational tools. The basis of import substitution is stably functioning enterprises. In this regard, the most important issue is not so much the organization of new industries, but rather creation of mechanisms to ensure the continuity of the existing ones, near which small and medium-sized enterprises can be created and included in closed process chains, or new plants can be also set on the areas and infrastructure of existing large enterprises of agro-industrial complex (Shabalina, Kopteva, 2019) [13,14].

It is about creating a comprehensive mechanism (tool) that will be used in a specific region and a specific enterprise. According to experts, it is impossible to build a universal mechanism of import substitution that would work equally effectively in each region and in every industry. However, a general scheme is needed, that would predetermine the general logic of this process in which all levels of government, business structures and agricultural enterprises should participate. At the same time, it is important to clearly distribute the 
powers, while the mechanism itself is not complicated (Fig. 5).

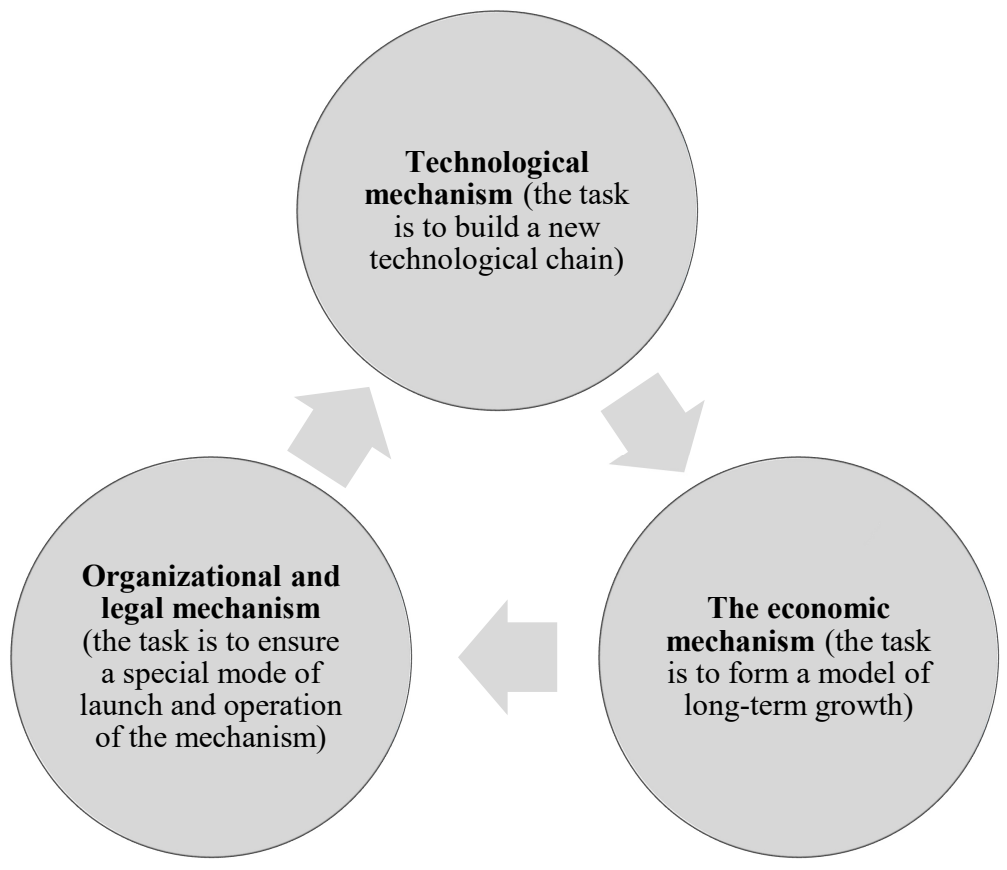

Fig. 5. The mechanism of import substitution activation.

Thus, the effective functioning of agro-industrial complex enterprises assumes the availability of a modern high-tech industrial and economic system with the task of producing modern competitive products not only for the domestic but also for the external market, which will require a fairly long period of time.

The research conducted shows that the agro-industrial complex of the Russian Federation has the potential for development, which can provide the population with foodstuff without resorting to products from the external market. For this, it is necessary to formulate a mechanism for state regulation of import substitution of the agro-industrial complex in the conditions of self-sufficiency of state in food products. In this regard, it is necessary, according to experts, to solve a number of problems: to ensure annual growth in production and sales of agricultural products of at least $1-1.5 \%$; to increase the competitiveness of the agricultural products; to develop logistics infrastructure of the agricultural market; to introduce modern technologies at agricultural business enterprises or renovate applied ones; to integrate national producers into the supply chain; to attract investment in the improvement and social infrastructure of rural settlements; to create conditions for attracting and retaining skilled labor resources in the agricultural sector. The solution of the listed tasks will allow both the development of all sectors of the agroindustrial complex and the consumer market.

It is expected that measures of state regulation of the policy of import substitution in the agricultural sector in conditions of self-sufficiency in food of the Russian Federation will contribute to: improving the standard of living of the state's population, which will lead to economic and physical accessibility of basic foodstuffs; increasing the interest of scientific institutions in attracting specialists to scientific research in the agricultural sector, as well as the introduction of scientific results in production; creating added value - from the production of agricultural machinery and equipment to the release of final products throughout the chain; increase export potential; creating the necessary conditions for doing 
business and the effective development of the agricultural sector, which can occupy an adequate place in the global food market (Shabalina, Kopteva, 2018) [15].

The measures discussed will contribute to the qualitative replacement of imports in the Russian food market with national goods, which will ensure the food independence of the state. It should also be taken into account that the Government of the Russian Federation has set the task of increasing the volume of exports of agricultural products, which must comply not only with the veterinary and sanitary requirements of the Russian Federation, but also with the requirements of importing countries.

\section{Conclusion}

The formation of a mechanism for state regulation of import substitution in the agroindustrial complex in conditions of self-sufficiency in food stuff of the Russian Federation will help to ensure a balance of interests between the state, the population and business. The proposed measures for the development of the Russian agricultural industrial complex in the context of import substitution can lead to the following positive results: an increase in the share of the main types of agricultural products in the national market; an increase in the share of domestic products in the total volume of retail food products; increasing the share of national products in the main markets of agricultural equipment; the growth of the share of innovative products in the total volume of agricultural production; increase the level of technological production and labor productivity; reduce unemployment among the rural population.

Digitalization of agriculture and promising areas of scientific and technological development of agricultural production is associated with the formation of new high-tech markets and will allow to create analytical platforms for all involved parts of the agricultural sector; use smart technologies and industrial robots; track products movement from "farmer to the table" on the basis of blockchain and electronic exchange platforms for the sale of agricultural products, create a digital base for decision support systems in the agricultural sector.

The proposed model of state regulation of import substitution mechanism in the agricultural sector in the context of self-sufficiency in food of the Russian Federation will make it possible to specify each of the stages, as well as to monitor the fulfillment of tasks, which will create the preconditions for a subsequent export-oriented model of agricultural development.

\section{References}

1. D. Patrushev, On the development strategy of agriculture and fisheries for the period up to 2030. Report at the Government Meeting (2020) http://government.ru/dep_news/39226/

2. G.B. Kleiner, Issues of Economics 10, 21-25 (2013)

3. S.D. Bodrunov, Theory and practice of import substitution: lessons and problems: monograph (INIR S.Yu. Witte, St. Petersburg, 2015)

4. V.A. Plotnikov, Yu.V. Vertakova, Economics and Management 11(109), 38 - 47 (2014)

5. Food and Agriculture Organization of the United Nations, http://www.fao.org/docrep/005/y4252e/y4252e04.htm\#TopOfPage

6. L.A. Kopteva, D.E. Smolnitskaya, XVIII International Scientific and Practical Conference "Youth and Science" (AESA, Almaty), 302-306 (2019) 
7. Agricultural market review. Research Center Deloitte (2018) http: // https: //www2.deloitte.com/.

8. About the State program for the development of agriculture and regulation of agricultural products, raw materials and food markets for 2013-2025. Decree of the Government of the Russian Federation of July 14, $2012 N 717$ (as amended on November 10, 2017), http://www.consultant.ru/

9. R.E. Mansurov, A. Zasedova, Effective crisis management 2(101), 40-43 (2017)

10. N. Shagayda, V. Uzun, Economics 5, 63-78 (2015)

11. A. Mottaeva, A. Ivashchenko, A. Ryattel, E3S Web of Conferences 164, 10038 (2020) https://doi.org/10.1051/e3sconf /202016410038

12. On approval of the Doctrine of Food Security of the Russian Federation. Decree of the President of the Russian Federation dated January 30, 2010 No. 120, http://www.consultant.ru

13. V. Holodkova, A. Mottaeva, T. Pokrovskaya, E3S Web of Conferences 164, 11043 (2020) https://doi.org/10.1051/e3sconf /202016411043

14. L. Shabalina, L. Kopteva, E. Kashirina, E3S Web of Conferences 91, 06011 (2019) DOI:20199106011

15. L. Shabalina, A. Prorokov, L. Kopteva, MATEC Web of Conferences 170, 01002 (2018) DOI:201817001054 